\title{
Nanostructured Dye Sensitized Solar Cells with Different Counter Electrodes
}

\author{
Fahim Karim ${ }^{1}$, Ahmed Sikder ${ }^{1}$, William Ghann ${ }^{1}$, Kara Green ${ }^{2}$, Birol Ozturk ${ }^{2}$, Meser M. Ali ${ }^{3}$, \\ Jamal Uddin ${ }^{1, *}$ \\ ${ }^{1}$ Center for Nanotechnology, Department of Natural Sciences, Coppin State University, Baltimore, MD, USA \\ ${ }^{2}$ Department of Physics and Engineering Physics, Morgan State University, Baltimore, USA \\ ${ }^{3}$ Department of Neurosurgery, Cellular and Molecular Imaging Laboratory, Henry Ford Hospital, Detroit, MI, USA
}

Email address:

juddin@ coppin.edu (J. Uddin)

${ }^{*}$ Corresponding author

\section{To cite this article:}

Fahim Karim, Ahmed Sikder, William Ghann, Kara Green, Birol Ozturk, Meser M. Ali, Jamal Uddin. Nanostructured Dye Sensitized Solar Cells with Different Counter Electrodes. American Journal of Physical Chemistry. Vol. 9, No. 1, 2020, pp. 1-8.

doi: 10.11648/j.ajpc.20200901.11

Received: March 18, 2020; Accepted: April 8, 2020; Published: May 14, 2020

\begin{abstract}
Dye sensitized solar cells are devices that convert visible light into electricity using a dye sensitizer. They are generally low-cost, easy to make and environmentally friendly. Research in this field have mainly been focused on enhancing the performance of the devices through the optimization of its components such as the dye sensitizer and cathode. In this study, the performance of dye-sensitized solar cells fabricated with different cathode materials were tested. The experiments were carried out with one synthetic dye (N719) and two natural dyes (Pomegranate and Blueberry fruit dyes). Different cathode materials tested included thermally platinized, graphite-coated, and soot-covered Fluorine doped Tin Oxide (FTO) electrodes. The surface morphology of the different cathode materials was examined using Field Emission Scanning Microscopy and Energy-dispersive X-ray spectroscopy. The solar-to-electric energy conversion efficiencies of the devices were determined under full light illumination $\left(100 \mathrm{mWcm}^{-2}\right.$, AM 1.5 Global), and the electrochemical impedance studies were carried out and compared. The efficiency of the solar cells fabricated with the graphite-based cathode electrode were determined to be higher compared to the other cathode materials used in the study. These impedance characterization results show that electron lifetimes and reaction resistances differ for the same dyes when used with different counter electrodes, providing varying photocurrent efficiencies.
\end{abstract}

Keywords: Cathode, Carbon, Graphite, Counter Electrode, Platinic Acid, N719

\section{Introduction}

The Dye Sensitized Solar Cell (DSSC), first reported by Michael Grätzel and his co-workers in 1991, is a thirdgeneration solar cell which has generated a lot attention since its discovery [1-3]. The popularity of the device stems from its valuable characteristics such as low cost, easy fabrication process, and environmental friendliness [4-6]. Research in DSSCs have mainly focused on improving the efficiency of solar-to-electric energy conversion through modification of the components of DSSC - such as the counter electrode, titanium dioxide, photosensitizer dye, redox electrolyte, and conductive glass slides [7-11]. Between these, most of the investigations on dye sensitized solar cells have been focused on the development of sensitizing dyes [12-16]. Both natural and synthetic dyes have been investigated for use in the fabrication of high-performance dye sensitized solar cells [17-19].

The dye sensitized solar cell is composed of a photoanode, a counter electrode, and an electrolyte. The photoanode consist of titanium dioxide $\left(\mathrm{TiO}_{2}\right)$ coated transparent conductive electrode with sensitizing dye anchored on the surface of the nanocrystalline $\mathrm{TiO}_{2}$ for the absorption of sunlight. When light is incident on the solar cell dye molecules embedded in the $\mathrm{TiO}_{2}$ nanoparticles absorb photons and are excited from the highest occupied molecular orbitals to the lowest unoccupied molecular orbital state. The photo-excited dye species subsequently injects an electron 
into the conduction band of $\mathrm{TiO}_{2}$ electrode and becomes oxidized. The oxidized dye species subsequently accept an electron from the redox-couple electrolyte and the ground state of the dye is restored. The injected electron is transported through the mesoporous $\mathrm{TiO}_{2}$ film to the conductive layer of transparent conductive electrode and is conducted through an external circuit to a load where the work done is delivered as electrical energy. The electron from the external load diffuses to the cathode where it gets transferred back to the redox couple electrolyte, and in this way the electrolyte gains back the electron that was transferred to the oxidized dye.

It has been shown that different cathode materials have different band gaps and have an impact on the performance of the solar cells [20-23]. Whereas the focus and goal of investigating the use of different dyes is the development of high efficiency dye sensitized solar cells, studies on different cathode material are generally geared towards producing low-cost cathode materials. Counter electrode collects electrons from the external circuit and catalyze reduction in the redox electrolyte system. Materials that have previously been used as cathode material include platinic acid, carbon materials, polymers, metal compounds, composite materials, and multiple compounds [24-26]. Among these, platinum is commonly used as the counter electrode material in dye sensitized solar cells. In this study, counter electrodes made from different materials were characterized and applied in the fabrication of dye sensitized solar cells.

\section{Experimental Section}

Degussa P25, the titanium dioxide powder, was purchased from the Institute of Chemical Education. Fluorine-doped Tin Oxide (FTO) transparent conductive glass slides were purchased from Hartford Glass Company, Hartford City, Indiana. Sodium hydroxide $(\mathrm{NaOH})$, acetone $\left(\mathrm{C}_{3} \mathrm{H}_{6} \mathrm{O}\right)$, ethanol $\left(\mathrm{C}_{2} \mathrm{H}_{5} \mathrm{OH}\right)$, and acetic acid $\left(\mathrm{CH}_{3} \mathrm{COOH}\right)$ were purchased from Sigma-Aldrich and were used without further purification. Graphite used in making cathode slides was purchased from Ted Pella, Inc., USA. Platinic acid was purchased from Fischer Scientific Company. Absorption spectroscopy was carried out with UV-3600 Plus from Shimadzu, MD, USA. Emission spectroscopy was measured with RF-5301PC from Shimadzu, MD, USA. $\mathrm{TiO}_{2}$ paste was printed on FTO glass using WS-650 Series Spin Processor from Laurell Technologies Corporation, PA, USA. Carbon paint used in making cathode slides was purchased from Ted Pella, Inc., USA.

The cell performance was measured using $150 \mathrm{~W}$ fully reflective solar simulator with a standard illumination of airmass 1.5 global (AM 1.5 G) having an irradiance of $100 \mathrm{~mW} / \mathrm{cm}^{2}$ (Sciencetech Inc.), London, Ontario, Canada. Photocurrent measurements were performed with a 600 Potentiostat/Galvanostat/ZRA from GAMRY Instruments (Warminster, PA). HOMO and LUMO calculations were carried out using Spartan'14 software from Wavefunction,
Inc., Irvine, CA, USA.

\subsection{Preparation of Photoanode}

The photoanode was prepared on a fluorine-doped $\mathrm{SnO}_{2}$ (FTO) conducting glass substrate in accordance to an earlier published report [14]. The FTO glass slides were cleaned with detergent solution, rinsed first with water, and then with ethanol. The slides were treated with aqueous solution of titanium tetrachloride and then rinsed again with water and ethanol. The FTO glass substrates were subsequently spin coated with $\mathrm{TiO}_{2}$ paste prepared from a mixture of $\mathrm{TiO}_{2}$ powder, acetic acid, and soap water.

The $\mathrm{TiO}_{2}$ coated FTO slides were annealed at $450^{\circ} \mathrm{C}$ for an hour and allowed to cool to room temperature. The thickness of the $\mathrm{TiO}_{2}$ layer was determined to be approximately $8 \mu \mathrm{m}$ by using Field Emission Scanning Electron Microscopy cross-sectional imaging.

\subsection{Cathode Preparation}

Different types of counter electrode materials prepared in this study include platinum, graphite, and soot. The conductive side of FTO glass slides were used as the substrate in the preparation of all types of counter electrodes. For the graphite counter electrode, the graphite paste is simply painted onto the conductive side of the slide. For soot, the glass slide is held over a candle until soot coats the conductive side of the slide. For platinum, conductive side of the slide is covered with platinic acid and the slide is annealed for 30 minutes in air, followed by immersion in $\mathrm{NaBH}_{4}$ for 2 hours.

\subsection{Construction of the DSSC}

After both the counter electrode and the photoanode have been separately prepared, the dye sensitized solar cell is assembled by placing one electrode on top of the other and applying the iodine/iodide electrolyte in between them. The solar-to-electric energy conversion efficiencies of the constructed cells are subsequently performed.

\section{Results and Discussion}

Dye sensitized solar cells are composed of the photoanode, a counter electrode and a redox electrolyte that fills the space between the two electrodes. Most studies have focused on the optimization of the photoanode materials (i.e. the dye sensitizer material that absorb radiant energy and generate electrons). This study focuses on the counter electrode used in dye sensitized solar cells. We used different cathode materials to identify the one that demonstrates the best efficiency. We also tested each type of cathode material with three different dye materials: A synthetic dye (N719) and two natural dyes (Pomegranate and Blueberry). Table 1 shows the results of the efficiency measurements of different types of cathode materials for each dye material used in the experiments. 
Table 1. Efficiency of Solar Cells with three different dye and three different cathode materials.

\begin{tabular}{llll}
\hline & N719 (\%) & Pomegranate (\%) & Blueberry (\%) \\
\hline Soot-coated FTO & 0.13 & 0.09 & 0.02 \\
Graphite-coated FTO & 1.33 & 1.02 & 0.75 \\
Platinized FTO & 0.11 & 0.17 & 0.28 \\
\hline
\end{tabular}

\subsection{UV-Vis Measurements}

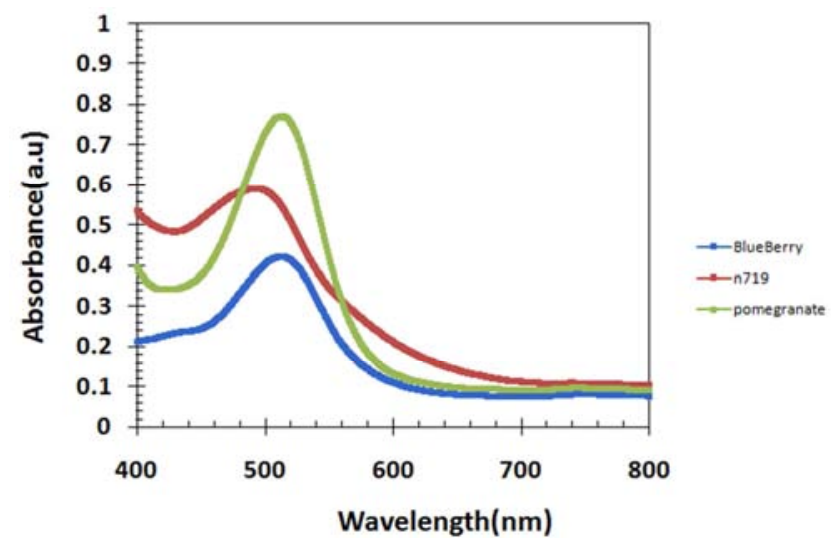

Figure 1. Absorption spectra of pomegranate dye extract (green), blueberry dye extract (blue), and N719 dye (red).

Figure 1 depicts the UV-VIS absorption characterization results of the dyes employed in this study. Both natural dyes of pomegranate and blueberry exhibited an intense absorption around $510 \mathrm{~nm}$, and this is attributed to the anthocyanin present in these dyes. The N719 dye had an
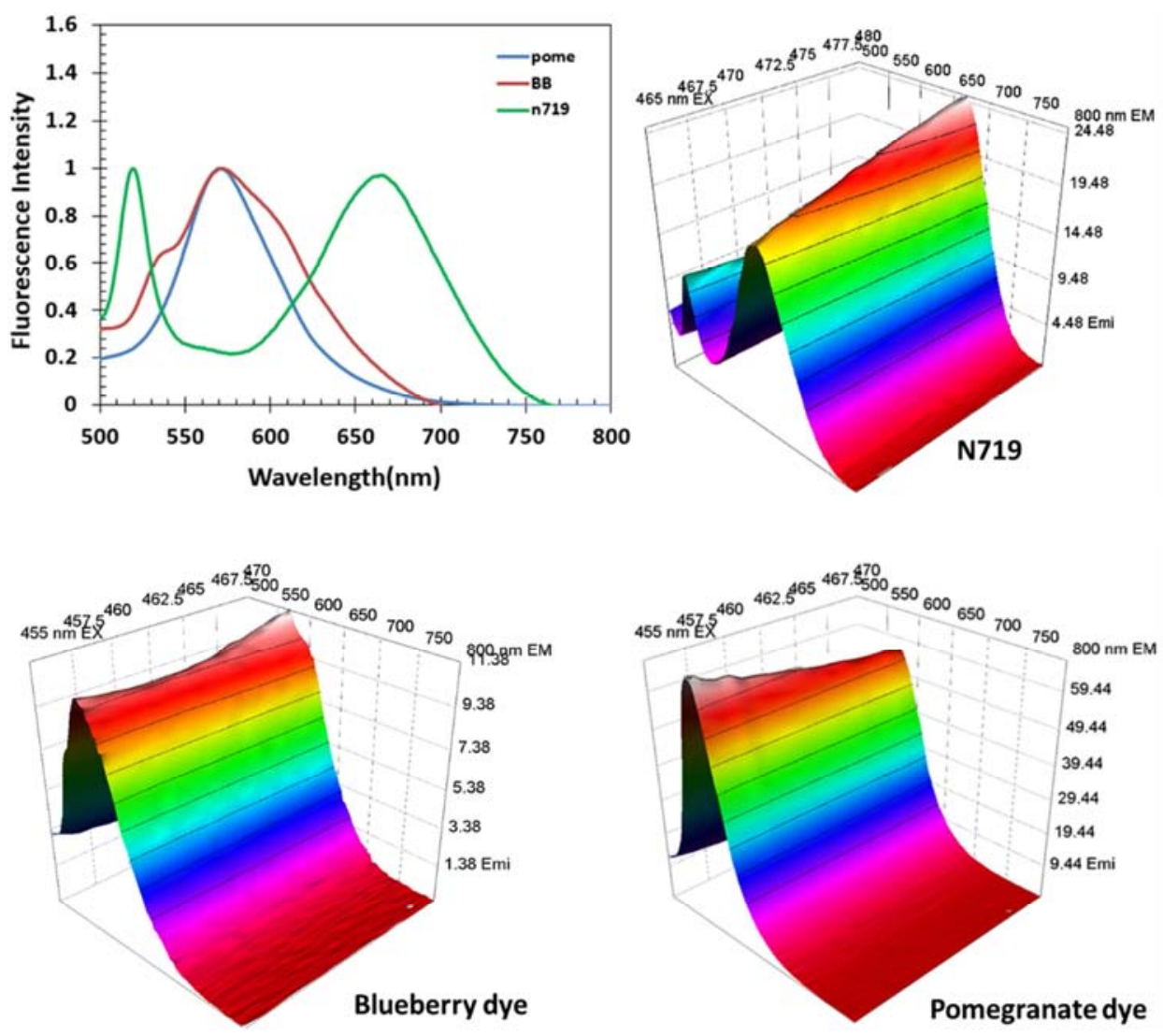

Figure 2. Comparison of the emission spectra of pomegranate dye (green), blueberry dye (blue), and N719 dye (red), and their corresponding individual $3 D$ emission spectra.

absorption band at around $490 \mathrm{~nm}$. All three dyes, however, have their absorption in the visible region, which allows the maximum conversion efficiency of the solar spectrum.

\subsection{Emission Studies of Dyes}

The steady state fluorescence spectra of N719 dye, Pomegranate dye extract and Blueberry dye extract were collected as part of the photophysical studies on the dyes and the results are displayed in Figure 2. The normalized spectra of all the three dyes are shown together and the 3D emissionexcitation plot of each dye is displayed separately. The measurement of N719 dye was carried out in ethanol. The central maximum emission wavelength for both Pomegranate and Blueberry dyes was $572 \mathrm{~nm}$ while the maximum emission wavelength for the N719 was $668 \mathrm{~nm}$ with an additional emission band at $519 \mathrm{~nm}$. The emission spectra show that all the dye utilized in the study emit in the visible region with that of N719 dye extending to the near infrared region. This characteristic along with that of their absorption properties, illustrate that the dyes can capture a high percentage of visible light upon excitation. 


\subsection{Field Emission Scanning Electron Microscopy}

The morphological characteristics of the three different counter electrodes were investigated via Field-Emission Scanning Electron Microscopy (FESEM). Figure 3 displays the FESEM images of the soot-coated, graphite-coated, and thermally-platinized FTO electrodes. The soot-covered FTO glass as seen in Figure 3 is the least granular, followed by the platinized FTO and the graphite-coated FTO glass. Counter electrodes catalyze the transfer of electrons from the external circuit back to the redox electrolytic system. The granulated nature of the electrode increases their surface area which is a very important property and a structural requirement for the counter electrode in dye sensitized solar cells.
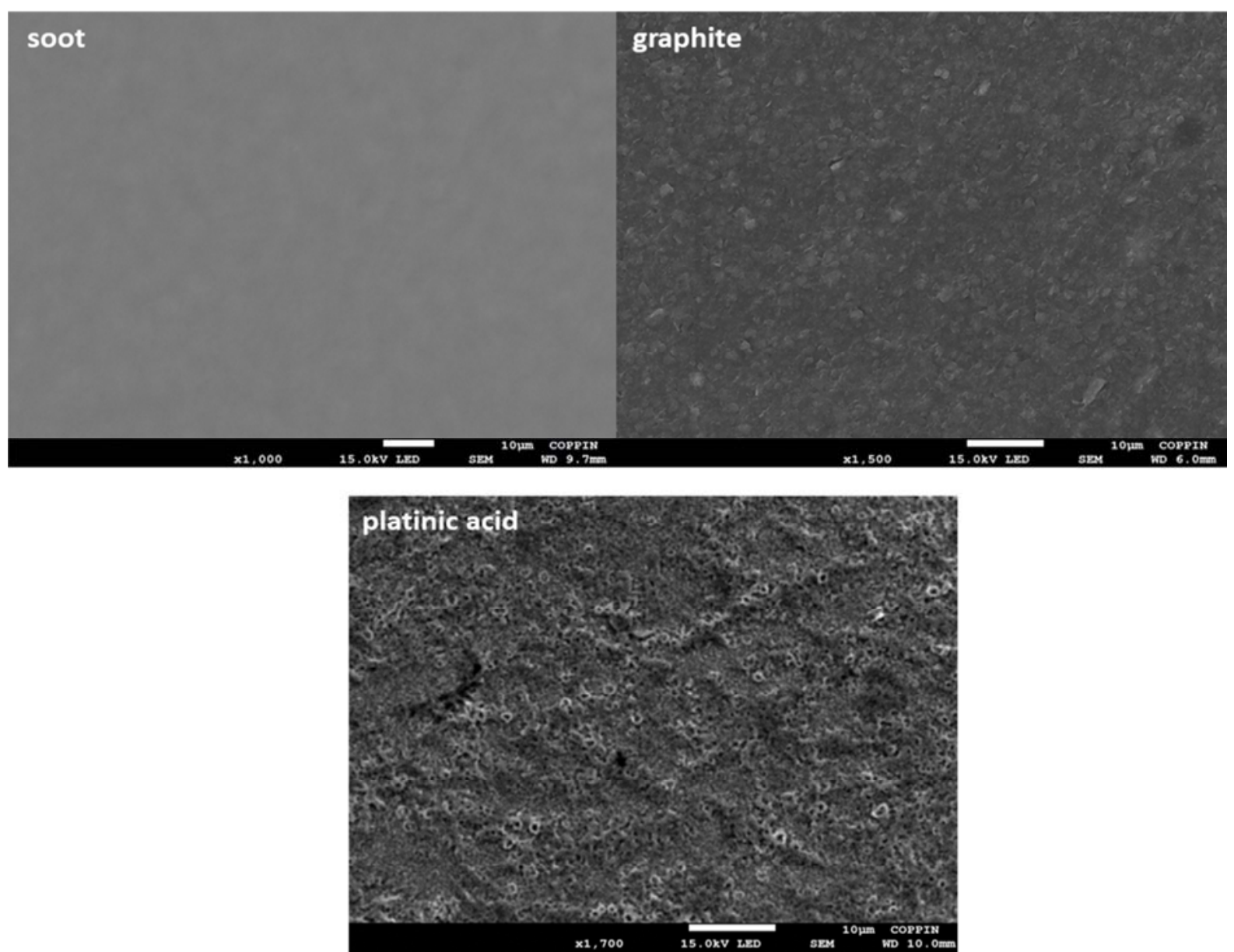

Figure 3. FESEM images of the three different materials on FTO glass slides used as cathode in dye sensitized solar.

\subsection{Energy-dispersive X-ray Spectroscopy}

Energy-dispersive X-Ray Spectroscopy (EDS) analysis was performed to confirm the elemental composition of the different cathode materials used in this study. The EDS spectra of the three cathode materials - soot, graphite, and platinic acid - coated on FTO glass slides are displayed in Figure 4. The spectra show that soot and graphite are mainly composed of carbon whereas the platinic acid coated FTO glass shows the presence of carbon, tin, platinum, chlorine and oxygen. The tin originates from the FTO glass substrate. Peaks of tin are absent from the graphite-coated FTO glass, which could indicate that graphite is evenly distributed on the surface of the glass and as a result, the conductive FTO layer is not in direct contact with the beam of electron. This could also explain why a higher solar-to-electric power efficiency was recorded for solar cells fabricated with the graphite material in comparison with the other two counter electrode materials.

\subsection{Current and Voltage Characteristics}

The current and voltage characteristics of the solar devices were tested under standard illumination of air-mass 1.5 global (AM $1.5 \mathrm{G}$ ) having an irradiance of $100 \mathrm{~mW} / \mathrm{cm}^{2}$. The efficiencies of the of the devices differed with respect to the type of counter electrode material used. In all the dyes used in the study, it was found that the performance of the solar cell with the graphite counter electrode was better compared to other two materials. The carbon soot-covered FTO had the poorest outcome. The efficiency of solar cells fabricated with graphite-based cathode was $1.33 \%, 0.75 \%$, and $1.02 \%$ with N719, Blueberry, and Pomegranate dyes, respectively. Figure 5 shows the current and voltage characteristics of the three different counter electrodes paired with the three different dyes. 


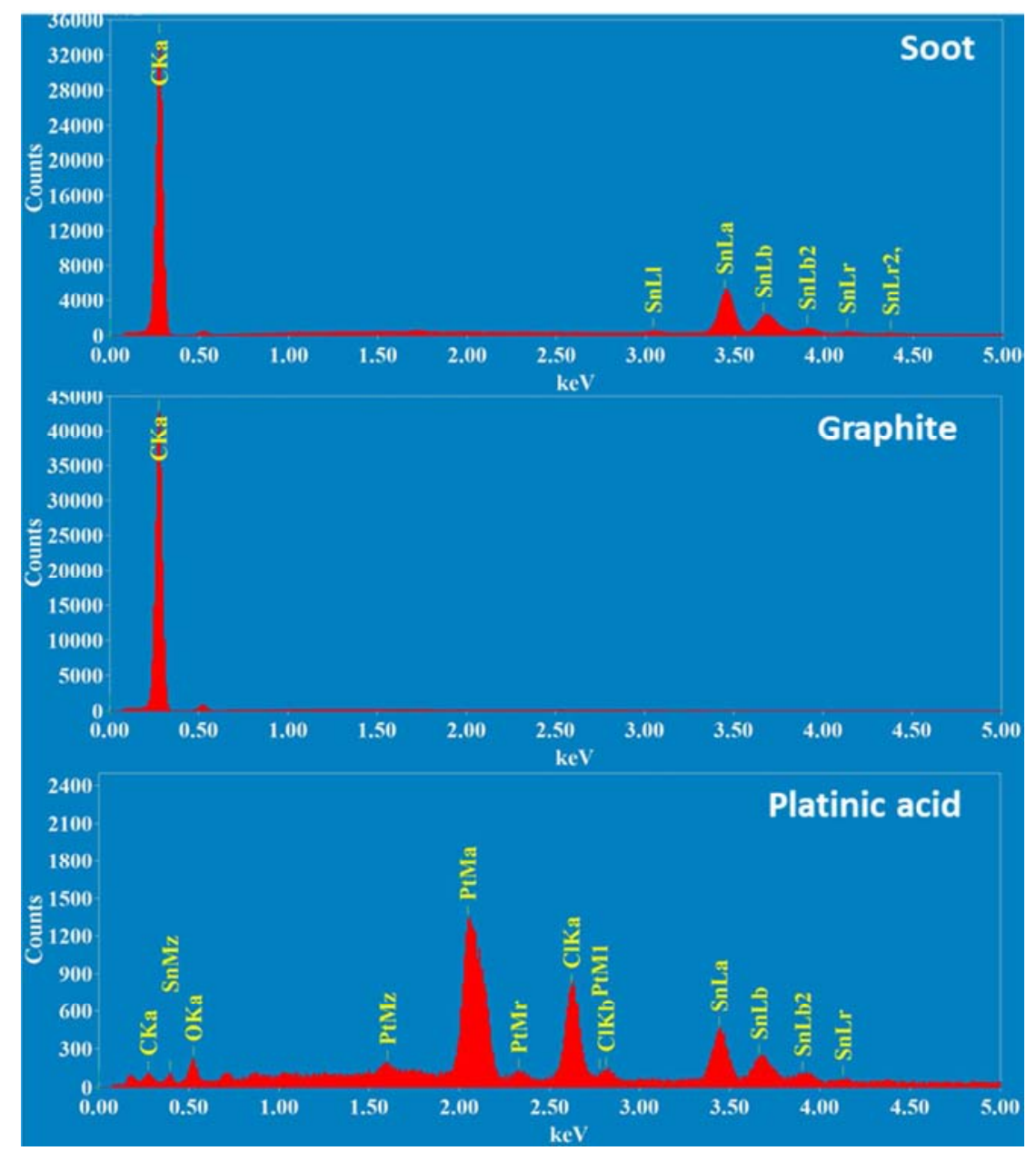

Figure 4. Energy-dispersive X-ray spectra of three different materials on FTO glass used as cathode in dye sensitized solar cells.
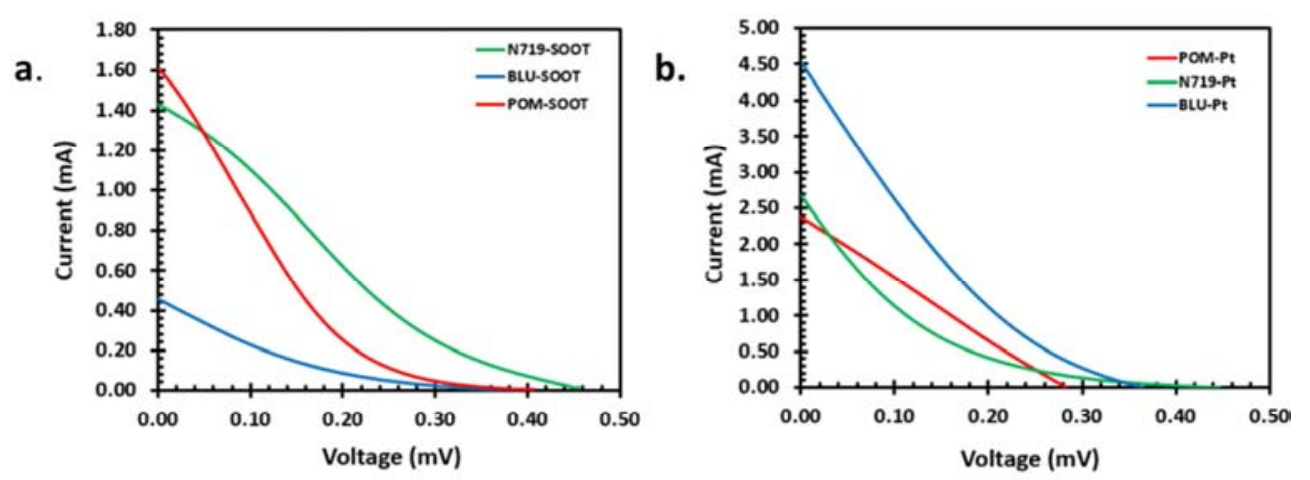

C.

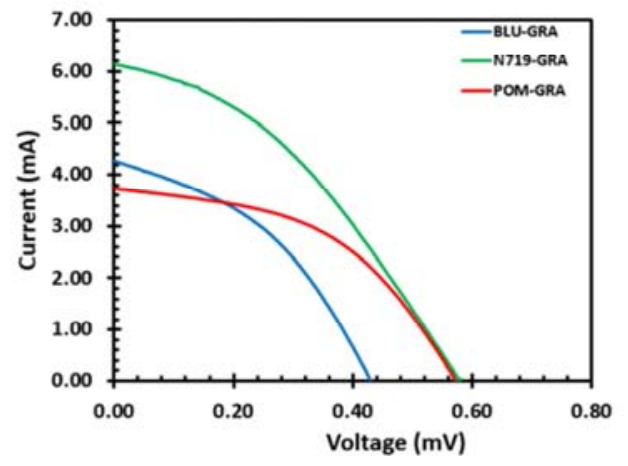

Figure 5. Photocurrent-voltage characteristics for dye sensitized solar cells fabricated with blueberry, pomegranate, and N719 as photoanodes with three different cathode materials under illumination of $100 \mathrm{~W} / \mathrm{cm}^{2}$ (1.5 AM) (a) soot; (b) platinic acid; (c) graphite. 


\subsection{Impedance Characterization}

The electrochemical impedance spectroscopy (EIS) was carried out on the dye sensitized solar cells fabricated with pomegranate, blueberry, and N719 as photoanode with three different cathode materials under illumination at AM 1.5G, $100 \mathrm{~mW} / \mathrm{cm}^{2}$. EIS is often used to evaluate the kinetics and energetics of charge transport and recombination in dye sensitized solar cells. The EIS characterization was performed in the frequency range between $1 \mathrm{~Hz}$ and $100 \mathrm{KHz}$. Figure 6 displays the Nyquist plots of dye sensitized solar cells fabricated with three different cathode materials when used with three different types of dyes. The increased radii of semicircles are indicative of higher charge transfer resistance. As shown in Figure 6a, the carbon soot counter electrode sample exhibited high reaction resistances with pomegranate and N719 dyes, which were manifested in the poor photocurrent performance of these solar cells. However, the blueberry dye with the carbon soot counter electrode featured the lowest photocurrent efficiency despite its low reaction resistance behavior in the Nyquist plot. In contrast, the blueberry dye displayed both the lowest resistance (Figure 6b) and the highest photocurrent efficiency when counter electrode material is platinized FTO. Although the reaction resistance of pomegranate dye was much higher compared to N719 dye as shown in Figure 6b, their photocurrent efficiencies were similar. The reaction resistances of all dyes were low for the graphitic counter electrode compared to other electrode materials, where N719 dye exhibited the lowest resistance. Furthermore, the high photocurrent efficiency measurements agreed with these low resistance values for the graphitic counter electrode.

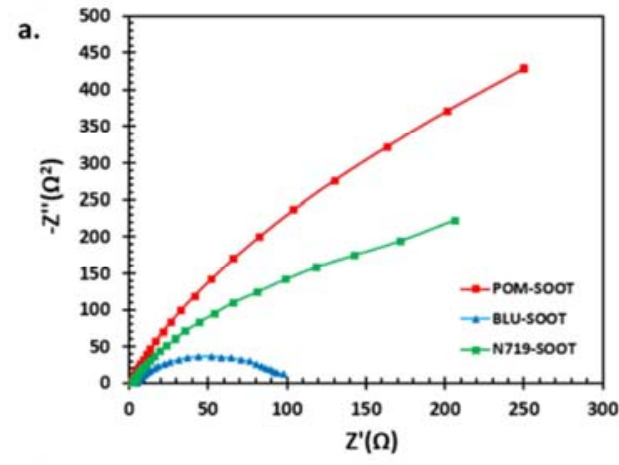

Figure 7 shows the Bode plot of the dyes for three different types of counter electrode materials. Bode plots are used to explore the charge-transfer kinetics of cathodes, where the electron lifetime is inversely proportional to the frequency and a lower charge transfer frequency result in a longer lifetime and vice versa. The longer electron lifetimes are desired for higher photocurrent conversion efficiency. Figure 7a shows that the peak frequency of N179 dye is the lowest and the blueberry dye is the highest for solar cells with carbon soot electrodes. These results are consistent with the photocurrent measurements as corresponding highest electron lifetime resulted in the highest efficiency for the N179 dye (Figure 5a) although it displayed the high reaction resistance in Nyquist analysis (Figure 6a). In contrast, the blueberry dye's lowest electron lifetime caused lowest photocurrent efficiency despite low reaction resistance behavior. The peak frequency of the pomegranate dye is the highest compared to other dyes when used with platinic counter electrode as depicted in Figure $7 \mathrm{~b}$, which agrees with low photocurrent efficiency along with the high reactive resistance behavior in Nyquist analysis. The middle semicircle appears as a shoulder in the blueberry dye Bode plot in Figure 7b, where the peak frequency is centered at around $30 \mathrm{~Hz}$. The notably high photocurrent efficiency (Figure 5b) of the blueberry dye compared to pomegranate and N179 dyes with platinic counter electrodes can be attributed to the low reaction resistance (Figure 6b) and the high photoelectron lifetime (Figure 7b). For the graphitic electrode, the N179 dye peak is located at a slightly higher frequency (shorter electron lifetime) compared to blueberry dye as shown in Figure $7 \mathrm{c}$, indicating that the low reaction resistance of N179 dye (Figure 6c) is more effective in its superior photocurrent efficiency (Figure 5c).

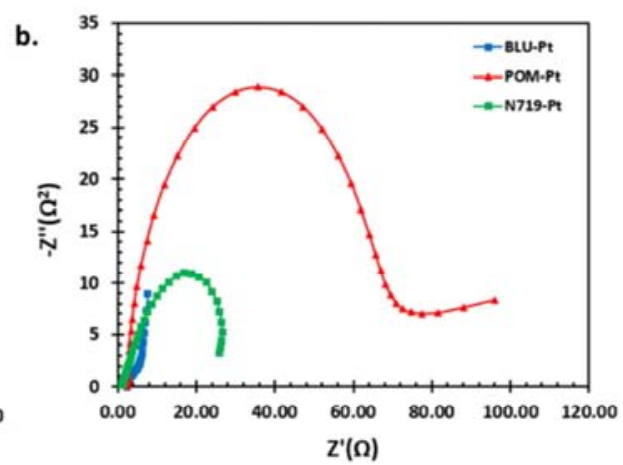

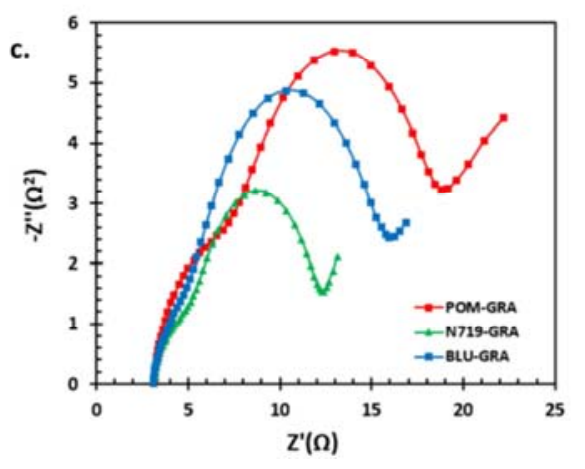

Figure 6. Nyquist plots for dye sensitized solar cell fabricated with pomegranate, blueberry, and N719 as photoanode with three different cathode materials (1.5 AM) (a) soot; (b) platinic acid; (c) graphite. 

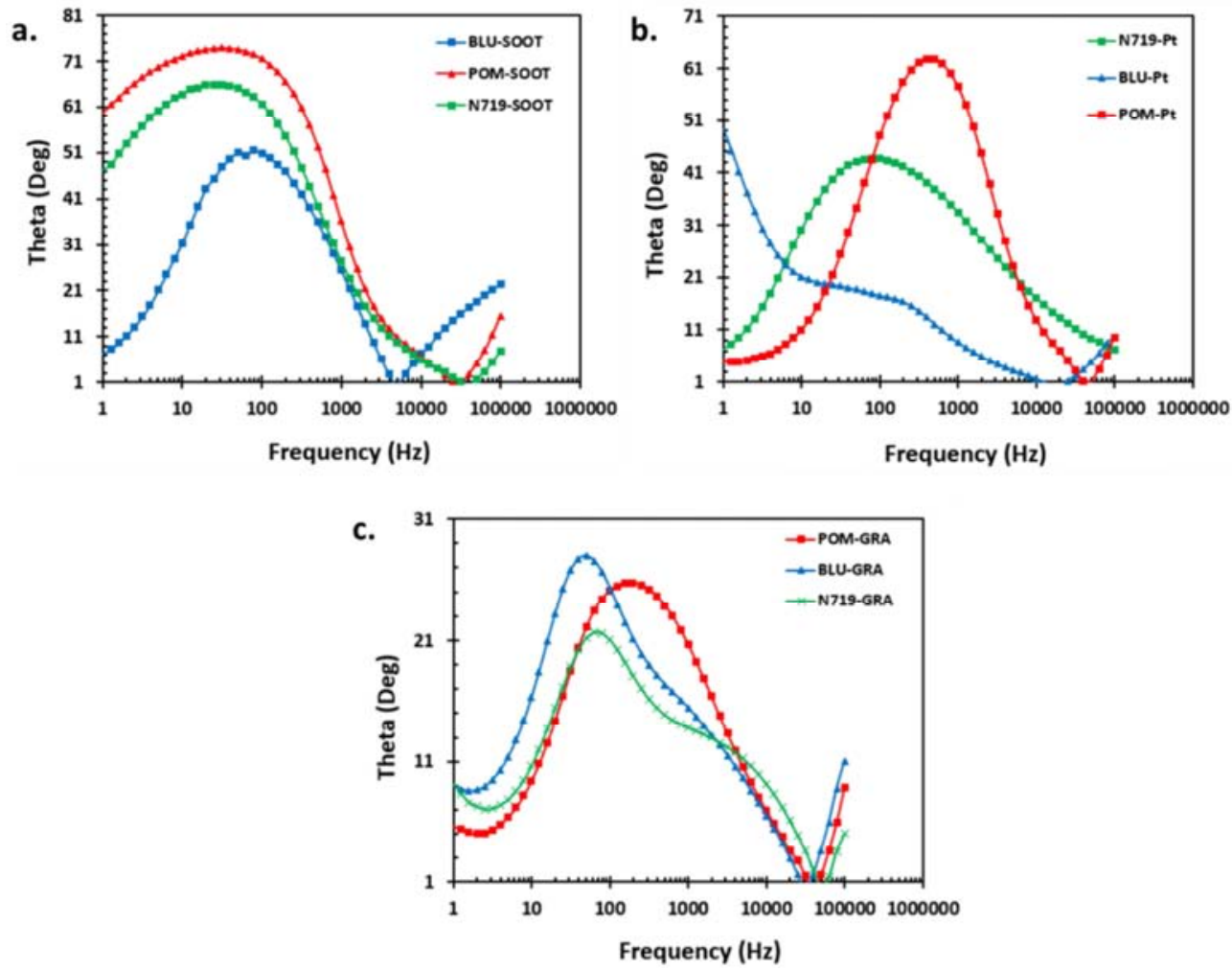

Figure 7. Bode plots for dye sensitized solar cells fabricated with pomegranate, blueberry, and $N 719$ as photoanode with three different cathode materials (1.5 AM) (a) soot; (b) platinic acid; (c) graphite.

These impedance characterization results show that electron lifetimes and reaction resistances differ for the same dyes when used with different counter electrodes, providing varying photocurrent efficiencies. Either electron lifetime or the reaction resistance plays a dominant role on the photocurrent conversion efficiency for the same dye depending on the counter electrode type.

\section{Conclusions}

Dye sensitized solar cells with different cathode materials were fabricated and their photovoltaic performances were determined. The tested cathode materials included thermally platinized, graphite-covered, and soot-covered FTO slide electrodes. The cathode materials were characterized with Field Emission Scanning Electron Microscope which showed that graphite-covered FTO electrode was highly granular with large surface area. These different cathodes were tested with dyes extracted from Pomegranate and Blueberry as well as the N719 synthetic dye. Dye sensitized solar cells fabricated with graphite-coated FTO electrode showed the highest solar-to-electric conversion efficiency.

\section{Acknowledgements}

This research project was partially supported by the University of Maryland System through Wilson E. Elkins Professorship grant, Constellation, an Exelon Company through E2- Energy to Educate grant program, and Department of Education through SAFRA Title III Grant.
The authors are also grateful to the Institution of Advancement, Coppin State University, for administrative help. The content is exclusively the responsibility of the authors and does not necessarily represent the official views of the funding agencies.

\section{References}

[1] Narayan, M. R. Review: Dye sensitized solar cells based on natural photosensitizers. Renew Sust Energ Rev, 2012, 16, 208-215.

[2] Ghann, W., Chavez-Gil, T., Goede, C. I., Kang, H., Khan, S., Sobhi, H., Nesbitt, F. and Uddin, J. (2017) Photophysical, Electrochemical and Photovoltaic Properties of PorphyrinBased Dye Sensitized Solar Cell. Advances in Materials Physics and Chemistry, 2017, 7, 148-172. https://doi.org/10.4236/ampc.2017.75013

[3] Athanas, A. B., Thangaraj, S., \& Kalaiyar, S. Co-sensitization of ruthenium (II) dye-sensitized solar cells by coumarin based dyes. Chemical Physics Letters, 2010, 699, 32-39. doi: 10.1016/j.cplett.2018.03.033.

[4] Hagfeldt, A., Boschloo, G., Sun, L., Kloo, L., \& Pettersson, H. Dye-Sensitized Solar Cells. Chemical Reviews, 2010110 (11), 6595-6663. doi: 10.1021/cr900356p.

[5] William Ghann, Hyeonggon Kang, Edward Emerson, Jiyoung Oh, Tulio Chavez-Gil, Fred Nesbitt, Richard Williams, Jamal Uddin, Photophysical properties of near-IR cyanine dyes and their application as photosensitizers in dye sensitized solar cells, In Inorganica Chimica Acta, 2017, 467, 123-131, ISSN 0020-1693, https://doi.org/10.1016/j.ica.2017.08.001. 
[6] Ghann, W., Kang, H., Emerson, E., Oh, J., Chavez-Gil, T., Nesbitt, F., Williams, R. Uddin, J. Photophysical properties of near-IR cyanine dyes and their application as photosensitizers in dye sensitized solar cells. Inorganica Chimica Acta, 2017, 467, 123-131. doi: 10.1016/j.ica.2017.08.001.

[7] Hosseinnezhad, M., Moradian, S. \& Gharanjig, K. Fruit extract dyes as photosensitizers in solar cells. Curr. Sci., 2015, 109, 953-956.

[8] William Ghann, Hyeonggon Kang, Tajbik Sheikh, Sunil Yadav, Tulio Chavez-Gil, Fred Nesbitt \& Jamal Uddin, Fabrication, Optimization and Characterization of Natural Dye Sensitized Solar Cell. Scientific Report, 2017, 7, 41470; doi: 10.1038/srep41470.

[9] Wu, M., \& Ma, T. Recent Progress of Counter Electrode Catalysts in Dye-Sensitized Solar Cells. The Journal of Physical Chemistry C, 2014, 118 (30), 16727-16742. DOI: $10.1021 / \mathrm{jp} 412713 \mathrm{~h}$.

[10] Kavan, L., Yum, J. H., \& Grätzel, M. Optically Transparent Cathode for Dye-Sensitized Solar Cells Based on Graphene Nanoplatelets. ACS Nano, 2010, 5 (1), 165-172. DOI: $10.1021 / \mathrm{nn} 102353 \mathrm{~h}$

[11] Hao, F., Dong, P., Luo, Q., Li, J., Lou, J., \& Lin, H. (2013). Recent advances in alternative cathode materials for iodinefree dye-sensitized solar cells. Energy \& Environmental Science, 2013, 6 (7), 2003. DOI: 10.1039/c3ee40296g.

[12] Wu, J., Lan, Z., Lin, J., Huang, M., Huang, Y., Fan, L., Wei, Y. Counter electrodes in dye-sensitized solar cells. Chemical Society Reviews, 2017, 46 (19), 5975-6023. DOI: $10.1039 / \mathrm{c} 6 \mathrm{cs} 00752 \mathrm{j}$.

[13] Syrrokostas, G., Siokou, A., Leftheriotis, G., \& Yianoulis, P. Degradation mechanisms of Pt counter electrodes for dye sensitized solar cells. Solar Energy Materials and Solar Cells, 2012, 103, 119-127. doi: 10.1016/j.solmat.2012.04.021.

[14] Tang, Z., Wu, J., Zheng, M., Huo, J., \& Lan, Z. A microporous platinum counter electrode used in dye-sensitized solar cells. Nano Energy, 2013, 2 (5), 622-627. doi: 10.1016/j.nanoen.2013.07.014.

[15] Zhang, D. W., Li, X. D., Li, H. B., Chen, S., Sun, Z., Yin, X.
J., \& Huang, S. M. Graphene-based counter electrode for dyesensitized solar cells. Carbon, 2011, 49 (15), 5382-5388. doi: 10.1016/j.carbon.2011.08.005.

[16] N. Alonso, M. Beley, P. Chartier and V. Ern, Rev. Phys. Appl., $1981,16,5-10$

[17] Desilvestro, J., Graetzel, M., Kavan, L., Moser, J., \& Augustynski, J. Highly efficient sensitization of titanium dioxide. Journal of the American Chemical Society, 1985, 107 (10), 2988-2990. DOI: 10.1021/ja00296a035.

[18] Vlachopoulos, N., Liska, P., Augustynski, J., \& Graetzel, M. Very efficient visible light energy harvesting and conversion by spectral sensitization of high surface area polycrystalline titanium dioxide films. Journal of the American Chemical Society, 1988110 (4), 1216-1220. doi: 10.1021/ja00212a033.

[19] Grätzel, M. Solar Energy Conversion by Dye-Sensitized Photovoltaic Cells. Inorganic Chemistry, 2005, 44 (20), 68416851. doi: 10.1021/ic0508371.

[20] M. Gratzel, Perspectives for dye - sensitized nanocrystalline solar cells. Prog. Photovoltaics, 2000, 8, 171-185.

[21] Hagfeldt, A., \& Grätzel, M. Molecular Photovoltaics. Accounts of Chemical Research, 2000, 33 (5), 269-277. doi: 10.1021/ar980112j.

[22] Goncalves, L. Bermudez, V., Ribeiroa H., and A. Mendes, Dye-sensitized solar cells: A safe bet for the future. Energy Environ. Sci., 2008, 1, 655-667.

[23] Gratzel, M. Acc. Chem. Recent Advances in Sensitized Mesoscopic Solar Cells Res., 2009, 42, 1788-1798.

[24] Ye, M., Wen, X., Wang, M., Iocozzia, J., Zhang, N., Lin, C., \& Lin, Z. Recent advances in dye-sensitized solar cells: from photoanodes, sensitizers and electrolytes to counter electrodes. Materials Today, 2015, 18 (3), 155-162. doi: 10.1016/j.mattod.2014.09.001.

[25] Lee, W. J., Ramasamy, E., Lee, D. Y., \& Song, J. S. Efficient Dye-Sensitized Solar Cells with Catalytic Multiwall Carbon Nanotube Counter Electrodes. ACS Applied Materials \& Interfaces, 2009, 1 (6), 1145-1149. doi: 10.1021/am800249k. 